Nasir Khokhar, M.D.

\begin{abstract}
:
Vitamin $K$ is an important substance in synthesis of several clotting factors, most important of which is prothrombin. Many antibiotics have effects on intestinal micro organisms which are necessary for synthesis of Vitamin $K$ and thus formation of essential clotting factors is interfered with. This antibiotic associated hypoprothrombinemia can lead to hemorrhage. Clinical set up for such a happening is generally easily recognized. Management includes parenteral administration of Vitamin K, plasma transfusion, or "Prothrombin Complex" in serious hemorrhagic conditions. Antibiotic associated hypoprothrombinemia can be prevented by prophylactic use of Vitamin $K$ in situations likely to result in bleeding, e.g. post-operative conditions.
\end{abstract}

Blood coagulation process is a complex cascade involving several factors. Vitamin $\mathrm{K}$ is very important in synthesis of several of these including factors II (Prothrombin), VII, IX, and X. Prothrombin is synthesized in the liver with Vitamin $\mathrm{K}$ as a co-factor which is required for gamma-carboxylation of glutamic acid residues in the final step of its biosynthesis. 1. Prothrombin is acted upon in the final common pathway by prothrombinase, which consists of other coagulation factors, to form thrombin which, in turn, acts on fibrinogen to result in formation of fibrin. A deficiency of Vitamin $\mathrm{K}$ results in synthesis of abnormal and hypofunctional prothrombin (and other Vitamin K dependent factors), which impair normal coagulation process with consequent bleeding problems.

\section{Etiology and Pathogenesis}

Hypoprothrombinemia results either from deficiency of Vitamin K or by decreased utilization by the liver. In addition, there are other causes which can lead to hypoprothrombinemia (Table I). Synthesis of the vitamin by the gut flora is an important endogenous source. Elimination of these bacteria by the use of potent antibiotics deprives the body of this important source. When such a situation is accompanied by a decreased oral intake, this could give rise to an ideal setting for the deficiency of Vitamin K.2,3 About $80 \%$ of patients in one series were on antibiotics when they developed Vitamin K deficiency. ${ }^{3}$ Surgical patients who may have received antibiotics to sterilize their bowels and had been kept without food and on intravenous fluids in the post-operative period constitute a common clinical setting for such a deficiency. This happens more frequently in the elderly. Neither nutritional deficiency nor gut sterilization alone usually result in Vitamin $\mathrm{K}$ deficiency, probably due to low daily requirement, as total starvation for four weeks did not produce such deficiency. ${ }^{4}$ This setting, how-

From the Department of Internal Medicine,

Pekin Memorial Hospital, Pekin, Illinois

Address all correspondence to Nasir Khokhar, M.D.,

Chairman, Department of Medicine,

Pekin Memorial Hospital, Pekin, IL ever, is not limited to surgical patients as medical patients on antibiotics and particularly those with renal disease and cancer also developed Vitamin K deficiency associated hypoprothrombinemia. 2,3

Many antibiotics (Table II) have been reported to have caused hypoprothrombinemia by eliminating the gut flora if used for long enough times. This happens more in the elderly patient with poor oral intake who is on more than one antibiotic at a time. Deficiency becomes apparent generally about the seventh day of

TABLE I

CAUSES OF HYPOPROTHROMBINEMIA

1. Decreased synthesis due to Vitamin K deficiency

i. Dietary deficiency

Newborn

$\mathrm{NPO}$ in post-operative patient

ii. Poor absorption

a. Gastrointestinal disorders

Malabsorption

Celiac disease

Inflammatory Bowel disease

Fistula

b. Unavailable bile salts

Absent: Obstructive jaundice

Bound: Cholestyramin

iii. Decreased gut synthesis

a. Not enough colonization

Newborn

b. Interference with bacterial action

Antibiotics (Table II)

Excessive Vitamin $A^{9}$

iv. Vitamin K Antagonists

Excessive Vitamin $\mathrm{A}^{9}$

2. Decreased utilization due to liver disease

Infectious and toxic hepatitis, cirrhosis

3. Interference with action of prothrombin

Coumarin drugs

Salicylates 10

Lupus inhibitors?

4. Destruction of prothrombin

Tropical American pit viper ${ }^{10}$

5. Vitamin $\mathrm{K}$ sensitive hypoprothrombinemia in pregnancy ${ }^{H}$ 
TABLE II

ANTIBIOTICS REPORTED TO HAVE INDUCED HYPOPROTHROMBINEMIA SECONDARY TO VITAMIN K DEFICIENCY

\begin{tabular}{|c|c|}
\hline Penicillin 3,5 & Sulfa ("Septra") ${ }^{3.5}$ \\
\hline Ampicillin ${ }^{3}$ & Streptomycin 3,5 \\
\hline Cloxacillin ${ }^{3}$ & Gentamycin ${ }^{3}$ \\
\hline Cephalosporin & Kanamycin ${ }^{3}$ \\
\hline Cephaloridine ${ }^{3}$ & Neomycin 5 \\
\hline Cefamandole 12,13 & Erythromycin ${ }^{3}$ \\
\hline Moxalactum This case, 13 & Tetracycline $3,5,6$ \\
\hline Cefoperazone ${ }^{13}$ & Chloramphenical 3,6 \\
\hline
\end{tabular}

antimicrobial therapy. ${ }^{3}$ These drugs presumably impair Vitamin K production by the intestinal bacteria flora by inhibiting synthesis of menadiones. $1,6 \mathrm{Cer}-$ tain cephalosporin may cause bleeding due to their chemical structure. ${ }^{13}$

\section{Manifestations}

Hemorrhage is the major feature of hypoprothrombinemia associated with antibiotic use. Bleeding can occur in the gastro-intestinal or genito-urinary tracts or intracranially. Ecchymosis, epistaxis, bleeding gums, or subconjunctival bleeding may occur and the patient may have some predisposing underlying factors like hypertension, peptic ulcer disease, and cystitis, etc. 11 Hemoptypsis in general is uncommon. ${ }^{10} \mathrm{~A}$ serious post-operative hemorrhage may occur and may be confused with disseminated intravascular coagulation (DIC). Gastro-intestinal hemorrhage, however, is commonest $^{6}$ as is seen in the following case.

\section{Case Report:}

This 91 year old female was admitted with a diagnosis of ischemic heart disease and bronchitis. She was weak and refused to eat. A chest roentgenogram showed bilateral pneumonia. She was treated with intravenous Gentamycin and Moxalactum with improvement of respiratory symptoms and decrease in temperature. On the sixth day of treatment, the patient had massive upper and lower gastro-intestinal bleeding with drop in hemoglobin of $\mathbf{2}$ grams which required a transfusion of packed cells. Coagulation profile revealed Protime (PT) of 55 seconds (Control $11.5 \mathrm{sec}$.), partial thromboplastin time (PTT) of 63 seconds (Control $35 \mathrm{sec}$.), platelets of 496,000 , and normal bleeding time. Several doses of Vitamin K were given intramuscularly (Table III) with rapid restoration of PT and cessation of bleeding. Prophylactic Vitamin $\mathrm{K}$ was given intramuscularly for further four days and a full course of antibiotics was completed without any further hemetemesis or malena. Meanwhile, her general condition improved, and she was able to eat regular food.

TABLE III

EFFECT OF VITAMIN K IN HYPOPROTHROMBINEMIA

$\begin{array}{llllll}12 / 3 / 82 & 12 / 4 & 12 / 4 & 12 / 4 & 12 / 5 & 12 / 8\end{array}$

\begin{tabular}{|c|c|c|c|c|c|c|}
\hline PT (seconds) & 55 & 39 & 22 & 13 & 15 & \\
\hline PTT (seconds) & 63 & 55 & 34 & & & \\
\hline Platelets & 496,000 & & & & & \\
\hline $\begin{array}{l}\text { Packed cell } \\
\text { transfusion }\end{array}$ & 2 units & & & & & \\
\hline $\begin{array}{l}\text { Vit. K IM } \\
\text { (mg) }\end{array}$ & 10 & 10 & 10 & & 10 & \\
\hline Gentamycin & IV & IV & IV & IV & IV & Stopped \\
\hline Moxalactum & IV & IV & IV & IV & IV & Stopped \\
\hline Bleeding & yes & yes & yes & no & no & no \\
\hline
\end{tabular}

\section{Comment:}

This case has perfect clinical setting for antibiotic related hypoprothrombinemia. The patient is elderly, not eating well, and on combination broad spectrum antibiotics. An associated structural defect of gastrointestinal tract is a possibility, but this, unfortunately, could not be determined due to patient's refusal of undergoing any further diagnostic tests.

\section{Management}

Diagnosis is usually easy, keeping in mind the clinical setting, ${ }^{2}$ prolonged PT and its prompt correction after the administration of Vitamin K. ${ }^{3}$ Bleeding time, platelet count, and factors not dependent on Vitamin $\mathrm{K}$ are not influenced."

Parenteral administration of Vitamin $\mathrm{K}$ is considered to be the effective treatment. Vitamin $K_{\text {, }}$ (Phytonadione), is given intramuscularly in $10-20 \mathrm{mg}$ doses and generally abolishes coagulation abnormalities within 24 hours (Table IV). Higher doses may, sometimes, be needed. Inadequate response should indicate complicating processes like liver disease or

TABLE IV

TREATMENT OF HYPOPROTHROMBINEMIA

MODALITY

1. Vitamin $\mathrm{K}$

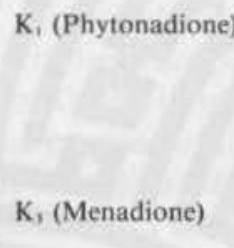

\section{K, (Menadione)}

2. Plasma

3. "Prothrombin Complexes"

\section{DOSAGE}

10-20 mg IM or PO as needed

10-20 mg $1 \mathrm{M}$ or $\mathrm{PO}$ as needed

$500 \mathrm{ml}$ and as needed

1-2 infusions as needed
COMMENTS

Rapid IV administration may cause flushing, dyspnea, death

\section{May cause} hemolytic anemia hyperbilirubinemia 
DIC, etc. If underlying defect cannot be rectified soon, small doses can be given daily to prevent bleeding until the cause can be eliminated. Synthetic Vita$\min K_{3}$ (menadione), may give a transient response than natural Vitamin $K_{1}$. Rapid intravenous administration of phytonadione may result in flushing, dyspnea, chest pain, and rarely death. ${ }^{10}$ Moderate doses of menadione have caused hemolytic anemia, hyperbilirubinemia, and kernicterus in newborn, especially premature and those with congenital glucose 6-phosphate dehydrogenase deficiency. 10, 11

Plasma transfusion may provide prothrombin (and other coagulation factors) and may be needed in severe bleeding." Replacement therapy with "Prothrombin complex" has been used in serious hemorrhage. Vitamin K deficiency acquired hypoprothrombinemia has been effectively corrected by commercially prepared parothrombin complex concentrate ("Konyne") when given in 1-3 intravenous infusions although there is some risk of post-transfusional hepatitis. ${ }^{8}$

Prevention of antibiotic associated hypoprothrombinemia essentially means awareness of the clinical setting in which it occurs. As Vitamin $\mathrm{K}$ deficiency induced coagulopathy is commonly an iatrogenic disorder with well known predisposing features, it has been recommended that Vitamin $\mathrm{K}$ supplements be added to intravenous fluids given to the patients undergoing major abdominal surgery who are on antibiotics; ${ }^{3}$ but special care is necessary since these patients are inclined to develop thrombo-embolic complications. 11

\section{Summary}

Antibiotics can induce hypoprothrombinemia due to Vitamin $\mathrm{K}$ deficiency by destroying intestinal bac- terial flora in association with poor oral intake, which can lead to varying degrees of hemorrhagic manifestations. The problem is easily recognized and can be promptly corrected by Vitamin $\mathrm{K}$ administration.

\section{References}

1. Wintrobe MM, et al: Clinical Hematology. Philadelphia, Pa., Lea and Febiger, 1981, pp 405-452, 1206-1246.

2. Ansell JE, Kumar R, Deykin D: The Spectrum of Vitamin K Deficiency. JAMA 238:40-42, 1977.

3. Pineo GF, Gallus AS, Hirsh J: Unexpected Vitamin K Deficiency in the Hospitalized Patients. Can. Med. Assoc. Jour. 109:880-883, 1973.

4. Firck PG, Riedler G, Brogli H: Dose Response and Minimal Daily Requirement for Vitamin K in Man. Jour. Applied Physio. 23:387-389, 1967.

5. Goldman H, Deposito F: Hypoprothrombinemic Bleeding in Young Infants. Am. Jour. Dis. Children. 111:430-432, 1966.

6. Klippel AP, Pitsinger B: Hypoprothrombinemia Secondary to Antibiotic Therapy and Manifested by Massive Gastrointestinal Hemorrhage. Arch. Surg. 96:266-268, 1968.

7. Breckenridge RT, Ratnoff OD: Studies on the Site of Action of a Circulating Anticoagulant in Disseminated Lupus Erythematosis. Am. Jour. Med. 35:813-819, 1963.

8. Sandler SG, Rath CE, Ruder A: Prothrombin Complex Concentrate in Acquired Hypoprothrombinemia. Ann. Int. Med. 79:485-491, 1973.

9. Green J: Antagonists of Vitamin K. Vit. and Hormones. 24:619-631, 1966.

10. Mandel HG, Cohen VH: Fat Soluble Vitamins in Gilman AG, Goodman LS and Gilman A (eds): The Pharmacologic Basis of Medical Therapeutics. New York. MacMillan Publishing Co. 1980, pp 1583-1601.

11. Deutsch E: Vitamin K in Medical Practice: Adults. Vit. and Hormones. 24:665-680, 1966.

12. Rymer W, Greenlaw C: Hypoprothrombinemia Associated with Cefamandole. Drug Intelligence and Clinical Pharmacy. 14:780-783, 1980.

13. Neu HC: Adverse Effects of New Cephalosporins. Ann. Int. Med. 98:415-416, 1983. 